Note: This is a pre-copy-editing, author-produced PDF of an article accepted for publication in Drugs: education, prevention and policy following peer review. The definitive publisher-authenticated version [McElrath $\mathrm{K}$ and McEvoy K (2001) Heroin as Evil: ecstasy users' perceptions about heroin, Drugs: education, prevention and policy, 8(2), 177-189] is available online at

http://www.informaworld.com/smpp/title db=all content=g713412766

\title{
Heroin as Evil: ecstasy users' perceptions about heroin
}

\author{
KAREN MCELRATH ${ }^{1}$ \& KIERAN MCEVOY ${ }^{2}$ \\ ${ }^{1}$ School of Sociology \& Social Policy and ${ }^{2}$ Institute of Criminology \& Criminal Justice, \\ School of Law, Queen's University, Belfast BT7 1NN, Northern Ireland
}

Published in Drugs: education, prevention and policy (2001) 8(2), 177-189

\begin{abstract}
Information gleaned from several studies suggests that non-opiate drug users view heroin and heroin users in negative terms. The present study examines this issue in greater detail through analysis of Ecstasy users' perceptions about heroin, heroin users and injectors. The data were collected through in-depth interviews with 98 current or former users of Ecstasy who were recruited through various methods in 1997-98. The findings confirm earlier reports and suggest that Ecstasy users tend to distance themselves from heroin users. The data also show that several Ecstasy users tend to believe that bad experiences with Ecstasy can be attributed to tablets laced with heroin. Explanations for these findings are offered.
\end{abstract}

\section{Prestige Hierarchy of Drugs Among Users}

Scholars, policy makers and laypersons often categorize illicit drugs in terms of 'soft' versus 'hard', 'recreational' versus 'addictive' [1]. Drug users also have been known to use these terms and some evidence has suggested that drug users tend to view drugs differently, depending in part on the drug in question. Specifically, information gleaned from several studies has shown that non-opiate drug users view heroin in negative terms (see, e.g. Klee, 1998; Parker et al. 1998; Solowij et al. 1992; Wibberley \& Price, 1998; Wright et al. 1999).

Non-opiate drug users have been known to describe heroin users in stereotypical terms and with scorn. For example, studies of amphetamine users in the North-West of England have shown that those respondents viewed heroin users as 'dirty' (Klee, 1998, p. 46), a finding that was replicated in a London study of recent users of Ecstasy, LSD or amphetamine sulphate (Power et al., 1996). Additionally, some amphetamine users have avoided treatment because they did not wish to be associated with heroin users (Wright et al., 1999, p. 75). In a New York study, researchers found that cocaine users 'felt superior' to heroin users and injectors (Dunlap et al., 1990). Similarly, a cocaine dealer interviewed by Coomber voiced a similar view in his description of heroin and heroin users as being 'dirty' (1997, p. 300). Other studies have shown that users of legal drugs (i.e. tobacco smokers and problem drinkers) tend to perceive 'heroin addicts' as dangerous (Finnigin, 1996). Drug users have been found to assess the addictive nature of specific drugs based in part on the individual traits of the person who consumes the drug rather than to its pharmacological properties (McKeganey \& Barnard, 1992). Relative to this finding, one report found that Ecstasy users (primarily from middleclass backgrounds) tended to believe that heroin is used primarily among persons in 'high unemployment areas' (Fraser et al., 1992, p. 13), a group that was geographically and culturally distinguishable from the interviewees.

\section{Background}

Until recently, much of the discussion regarding illicit drug use in Northern Ireland has been characterized by reference to the low prevalence levels. Drug use in Northern Ireland has been framed as minimal, and inevitably compared favourably to the 'more serious' drug problems of close regional neighbours such as the Republic of Ireland (namely Dublin) and Britain (McEvoy et al., 1998). 
However, in the wake of the paramilitary ceasefires, considerably greater public attention has focused on the dangers presented by a range of 'recreational' and 'dance' drugs (Hollywood, 1997). In the late 1990s such concerns have broadened to include alleged increases in heroin use, 'abuse' and availability (Belfast Telegraph, 1998, 1999; Turner, 1998) whereby former and current users of heroin have given interviews for local papers describing their 'heroin hell' and 'heroin horrors' (Belfast Telegraph, 1997a, 1997b). In 1998, news media described what was perceived to be the first 'heroin overdose' in Northern Ireland [2].

The limited data on heroin use in Northern Ireland makes it difficult to gauge the accuracy of these reports [3] and the validity of these claims is not our objective in this paper. Rather, we wish to explore the ways in which drug users employ comparative indicators (in this instance with other 'more serious' users) to both frame and understand their own usage.

During this period of growing attention to a potential heroin problem, the authors were involved in the fieldwork stages of a study of Ecstasy use in Northern Ireland. Shortly after the Ecstasy study commenced, and in response to local media and government interest in heroin use, we began to explore Ecstasy users' perceptions about heroin, heroin users and injection. These issues are the focus of this paper.

\section{Methods}

The present study is based on 98 in-depth interviews with current or former Ecstasy users in Northern Ireland (McElrath \& McEvoy, 1999). The criterion for study participation was `any use of Ecstasy'.

\section{Recruitment}

We used several methods to recruit respondents. First, we placed announcements or adverts of the study in cities, towns and villages throughout Northern Ireland. We targeted venues that generally would be perceived as non-threatening and likely to attract large audiences, e.g. record or music shops, health centres. Second, we advertised in a local club/music magazine that caters to a Northern Ireland population. The advert was published in three monthly issues during the study period. Third, we contracted several local organizations and notified them of our study. These agencies were diverse and included: youth outreach centres, universities, STD clinics, gay men and women outreach programmes, young offender programmes, and drug counselling or treatment centres. On several occasions we sent study announcements by post and then followed up with phone calls to or visited with agency staff in order to discuss the study in greater detail. Fourth, we asked interviewers to recruit some respondents through their own contacts and street sources. Fifth, we relied on snowball sampling, and asked respondents to refer friends and acquaintances. Sixth, in some instances we paid 'recruiters' for each subsequent referral and completed interview. This method, however, was monitored closely and we had a set number of referrals (usually six) from each recruiter that we would accept. This method was particularly helpful in those outlying areas where we had few contacts. Clubs were not used as recruitment venues.

\section{Interview Data}

Interviews were conducted between October 1997 and November 1998. Four persons, two females and two males, served as interviewers (two of whom were the Project Directors). All interviewers were trained during a 2-week period before the study commenced and throughout the study period during staff meetings and discussions. Training topics included issues related to confidentiality and other ethical concerns, interviewing skills, and drug and club information. Interviews in Belfast generally were conducted in university offices that offered a great deal of privacy, or in other venues convenient to the respondent (e.g. private homes). Interviews with respondents who lived outside of Belfast were conducted in private areas located within community agency sites or in private homes.

Respondents were assured of confidentiality and given a $£ 15$ music or book voucher for a completed interview. Interviews were conducted within a 1-2-hour time period and focused on issues related to first, last and usual use of Ecstasy, positive and negative drug experiences, drug use rituals and norms, health issues, and other items. Demographic and drug use history data also were collected.

\section{Description of Respondents}


Characteristics of the samples are reported for descriptive purposes only. Males comprised $69 \%$ of the sample and respondents' ages ranged from 17 to 45 years (mean `25; median `24; mode`23) [4]. Social class was self-identified; $49 \%$ of respondents described themselves as working class, $46 \%$ were middle class and $5 \%$ reported being 'between' working and middle class. Slightly over half of the sample (57\%) were employed in part- or full-time work.

Relative to other studies of Ecstasy use (e.g. Beck \& Rosenbaum, 1994; Solowij et al., 1992) our sample was comprised of a disproportionate number of 'heavy' users. For example, $44 \%$ of our sample had used Ecstasy on at least 100 different occasions. In contrast, 18\% has used the drug on 12 occasions or less [5]. Approximately three-quarters (77\%) of the respondents were current users of the drug, $18 \%$ of the sample were former users (i.e. had stated that they would not use Ecstasy again) and $5 \%$ were trying to stop using or were not certain whether they would use again.

The majority of respondents had tried a number of different drugs. Although several reported that cannabis was a favourite and the drug most often used, others indicated that hallucinogens, stimulants or depressants were the drugs of choice. Eleven per cent of the respondents had tried heroin through snorting, smoking or injecting [6], although only $5 \%$ had used heroin in the 6 months prior to the interview.

\section{Results}

\section{Views About Heroin and Injection}

In an Australian study, Ecstasy users were asked to rate Ecstasy on a scale of 0-10, in comparison to marijuana (coded 0) and heroin (coded 10). The average overall rating for Ecstasy was 4.67 (Solowij et al., 1992) , which suggests that Ecstasy users perceive heroin to be a substantially 'harder' drug than Ecstasy. Perhaps similar to the differentiation between 'soft' and 'hard' drugs, respondents in the present study tended to dichotomize drugs as being 'good' (e.g. Ecstasy) and 'not good' (heroin):

'I think people, probably people that are overly using drugs [that is, heroin] or who're maybe using drugs that simply are not good for them need help.' (110, female, age 33)

Users of Ecstasy were much more likely to view their own drug use in recreational terms, simply 'having a good time' whereas heroin users and injectors were not:

'As far as what [Ecstasy users are] doing, they're having a good time, recreational drug. I don't think most E users [would] see themselves as, as a junkie, so to speak, you know.' (015, male, age 29)

'They're [heroin users and injectors] not taking drugs for a recreational thing.' (121, male, age 38)

A number of Ecstasy users in the present study voiced negative images about heroin and injection:

'But at the same time I feel like it would be really nice to try a bit of cocaine and see what it's like ... whereas the likes of heroin doesn't appeal to me, it's a dirty drug . . . but cocaine is a bit more appealing.' (125, female, age 24)

'I would never, ever dream of doing it [heroin] myself. I can't imagine at any time [that I will] want to, not through fear of needles or anything like that, just I mean there is, kind of, a scummy kind of air around it . ..' (126, female, age 21)

$\because$... people living in scum ... trainspotting-type situation, just dirty, just caring about nothing ... that's how I imagine drug injection users.' (016, female, age 25)

We also observed that frequency of use was not related to attitudes about heroin. That is, value judgements about heroin users and injectors also were voiced by several 'heavy' users [7] of Ecstasy: 
'I generally think people who inject drugs have a drug problem.' (131, male, age 29, has consumed Ecstasy approximately 100 times during a 2- or 3-year period)

'Definitely sad, you know that's an abuse of your body ... So maybe it's a different type of abuse, but it's obvious what the abuse is ...' (205, male, age 30 , has consumed Ecstasy approximately 150 times over a 4 - year period)

[On injectors] 'I don't know how they've let themselves get that bad . . . you'd feel dirty doing it.' (306, male, age 28, has used Ecstasy over 100 times during a 3-year period)

Several respondents appeared to distance themselves from heroin users because the former associated the latter with drug injection. In these instances, it was the method of consuming the drug rather than the drug itself that contributed to negative perceptions:

'I think they're [injectors] mad. But if they've gone that far down the line [then] they need help, they are addicted to them.' ('125, female, age 24)

'... [injecting heroin is like] going down a different path.' (117, male, age 22)

'Injecting a thing, you're sitting there, tying your arm up, getting a vein out and putting something into your vein which is a lot different than buying a pill . . . and then dropping in your mouth.' (127, male, age 23)

Stereotypes and generalizations about injectors also were common ( $\ldots$. . on the street,' 122, male, age 25) and at times, in light of their own behaviour and lifestyle, some respondents' perceptions about injectors were hypocritical:

They should be shot - or forced to leave . . because they're a drain on the community.' (303, male, age 27 , unemployed heterosexual male who has consistently engaged in unsafe sex)

'[Injectors are] totally stupid.' (114, male, age 26, consumed 25 pints of beer and no water during his most recent use of Ecstasy)

Other respondents expressed linkages between heroin use and crime:

[Heroin] - it's very, very addictive ... if you get addicted badly, you'd have to steal for it, thinks like that ...' (309, male, age 19, has used Ecstasy more than 100 times; has ingested 13 tablets in one night; admitted stealing money from his employer on more than one occasion for the purpose of buying Ecstasy)

'Heroin causes quite a lot of crime 'cause people are stealing to fuel their habit . . in that there sense, they're causing a problem.' (009, male, age 21)

We examined whether people's experiences with Ecstasy might have contributed to negative views about heroin use and heroin users. Specifically, we examined whether former users of Ecstasy differed from current users, with respect to negative views about heroin and heroin users. Given the large number of 'heavy users' of Ecstasy in the sample, we also examined whether this trait was related to negative views about heroin. Finally, we analysed the relationship between negative perceptions and age of respondents.

Our measure of negative views about heroin or heroin users was a dichotomy, coded 1 for the presence of the trait (else ^ 0 ). Negative views included perceptions that were characterized by stereotypes, unfair judgements, and false information [8]. This coding method indicated that $42 \%$ of the respondents held negative beliefs about heroin or heroin users (no negative views ^ $49 \%$; question not asked` $9 \%$ ). The bivariate relationships are presented in Table 1. 
Approximately one-half (49\%) of the current users of Ecstasy held negative views about heroin and heroin users compared to $53 \%$ of the former users. These percentages reveal few differences in negative views by user status (current or former users of Ecstasy). Moreover, the results were not statistically significant [9]. With respect to lifetime use of Ecstasy, the data show that negative views about heroin were more often voiced by persons who had very limited experience with Ecstasy (2-12 episodes $54 \%$ ) and by persons who had consumed the drug on 100 occasions or more (51\%). In contrast, respondents who were grouped in the two middle categories (i.e. 13-49 episodes and 50-99 episodes) were less likely to hold views about heroin (47\% and $43 \%$, respectively). These differences, however, failed to reach statistical significance.

Table 1. Per cent reporting negative views about heroin and injection use/users by age, user status, and lifetime use of Ecstasy

\begin{tabular}{|c|c|c|c|c|c|c|c|}
\hline User status & \multicolumn{3}{|c|}{ Lifetime use of Ecstasy } & \multicolumn{4}{|c|}{ Age } \\
\hline Current & $13-49$ & $50-99$ & $100+$ & $17-21$ & $22-24$ & $25-28$ & $29+$ \\
\hline $53 \%$ & $54 \%$ & $43 \%$ & $51 \%$ & $46 \%$ & $57 \%$ & $42 \%$ & $39 \%$ \\
\hline $\begin{array}{l}\text { Chi-Square }=0: 083 \\
\mathrm{df}=1 \\
p=0: 78\end{array}$ & $\begin{array}{l}\text { Chi-Square }=0: 445 \\
\mathrm{df}=3 \\
p=0: 93\end{array}$ & & & $\begin{array}{l}\text { Chi-Squ } \\
\mathrm{df}=3 \\
p=0: 66\end{array}$ & $=1: 578$ & & \\
\hline
\end{tabular}

\section{Ecstasy Laced with Heroin}

One of the issues which we sought to explore in this study was the issue of whether Ecstasy users had taken (or believed they had taken) Ecstasy which had been laced with heroin. Although Ecstasy tablets are normally marketed as containing MDMA, tablets sold as Ecstasy also have been found to contain MDA, MDEA and a host of other drugs and adulterants (Lifeline, 1996) . In 1997 a user had about a one in three chance of getting MDMA in a tablet bought in Amsterdam and even less elsewhere (personal communication with Lifeline Manager, Alan Haughton, October 1997) [10]. The belief by some users that certain Ecstasy tablets contain heroin has been noted elsewhere (Forsyth, 1995) although dozens of independent studies conducted in England have yet to identify heroin in any tablet tested there (personal communication with Lifeline Manager, Alan Haughton, October 1997; Saunders, 1998) .

Although possible, it is unlikely that Ecstasy tablets do contain heroin. Financially, it is not costeffective for the manufacturer or dealer. In addition, even if, for example, an Ecstasy tablet contained heroin, the amount would be so small that when ingested orally, the heroin would not likely produce any noticeable effects for the user. Nevertheless, we asked respondents whether they had ever ingested an Ecstasy tablet that was laced with heroin. Although a majority of respondents, $75 \%$, reported that they had never consumed such tablets, a substantial number of respondents, $22 \%$, claimed to have taken an Ecstasy tablet that was laced with heroin [11]. The vast majority of these users recalled that the effects of the tablet were quite negative:

'I was sick . . . and drowsiness and I didn't know where I was.' (129, male, age 23)

'Heroin ... That happened to me actually the first time I took E . . I couldn't move, [my partner] was shit scared and when I did tell her, she was going to get an ambulance and I was totally smashed but then I felt numb, I couldn't speak. I couldn't focus or anything, I just wanted to sit in the middle there.' (125, female, age 24)

'floating ... your internal organs floating ...' (203, female, age 45)

Although most of the users in this study reported that their initial experience with Ecstasy was pleasant, a male respondent described his first experience as being negative and attributed this reaction to heroin [12]. He recalled, for example, that he was unable to have a conversation and noted that:

'... apparently this particular one I took that time was very heroin-based.' $(026$, male, age 30) 
Other respondents also tended to believe that heroin-laced tablets were likely to be the reason for a negative experience with Ecstasy:

$\therefore$ sometimes I think it may explain why l've been feeling really heavy or tired on an $\mathrm{E}$, it's maybe had smack or heroin in it.' (005, male, age 34)

$\because$.. there was maybe once I thought to myself, "I wonder, was there heroin in that?" Because the Monday after the Saturday night when l'd taken it I felt as if "Frig. I need to get another E here." It's not often you get that feeling where you have to get one but I nearly had that and I thought I wonder was that laced with something addictive you know.' (205, male, age 30)

Another respondent who had used Ecstasy about 1000 times in a 9-year period, described the 'worst E I ever took in my life' whereby he 'lost control':

'... I think they were laced with heroin or Ketamine ...' (204, male, age 27)

Ecstasy tablets sold in Northern Ireland and elsewhere in Europe often are labelled with various names (e.g. 'California Sunrise', 'Doves', 'Loony Tunes', 'Silver Dollars') and these labels appear to be an integral part of drug marketing. Respondents in this study suggested that Ecstasy tablets containing heroin could be identified by certain labels. For example, speckles were assumed to be heroin:

'The first one I had was a "White Dove" and "White Doves" are always very clean E. You can get "Speckled Doves", which have the brown speckles through them and "Speckled Doves" are notoriously smacky which is why you take it.' (001, male 24)

'Smacky Es, the smackier, the more there was heroin in them. They were normally speckled and black with brown flecks or such running through them. Ehm, they had a funky smell off them, a bit like cat's pee to be honest, ehm, they were chalkier.' (115, male, age 29)

Various forms of 'Doves' have been sold widely in Britain and in Ireland over the years and one user claimed:

" "Doves" are laced with heroin which makes them very calming and very easy for stress relieving. I've had "Doves" a few times and can't stand them. I don't want to calm down . . $\therefore$ (301, male, age 29)

In general, however, no consistent pattern emerged from the data that pointed to one particular 'brand' of Ecstasy that was laced with heroin:

'. . remember the "Special K" Es [that] were around? They were supposed to be laced with heroin." (204, male, age 27)

'. . [there was speculation that] Crowns had heroin in them.' (014, male, age 25, the respondent heard this claim from his supplier)

$\because$.. they were Playboys and somebody just told me that there was heroin or cocaine or something like that.' (119, male, age 21)

In reports published outside Northern Ireland, Ecstasy tablets marketed as 'Snowballs' were said to contain high dosages of MDA rather than heroin (Malyon, 1995; Milroy et al., 1996) and produced 'unpleasant reactions in some people' (Malyon, 1995, p. 41). A few respondents in the present study were convinced that 'Snowballs' contained heroin. The confusion, however, might reflect nomenclature [13]; a 'Snowball' in some cultures is street slang for a combination of heroin and cocaine: 


\begin{abstract}
'Years ago there was one Ecstasy tablet going around that was laced with heroin,
"Snowballs", I think they were called. [They were] very trippy, coming down, it lasted for about 5 hours, it was good. I actually laughed for 5 hours. It got a bit worrying at one stage, maybe that could have been one of the panicky things whenever I couldn't breathe because I was laughing so much.' (106, female, age 23)
\end{abstract}

However, ingesting the 'brand' was not a necessary requirement for the belief:

'I haven't taken 'Snowballs", but I know that there is heroin or cocaine in them.' (113, male, age 25)

We also observed that some Ecstasy users appeared to have limited knowledge about the effects of certain drugs as in the following claims that appeared to confuse the effects of opiates with those of hallucinogenics or stimulants:

'You talked about smacky E's. Did you mean, they were cut with smack [heroin]?'

'Well, they made you hallucinate. People say that they are laced with heroin, so maybe.' (010, male, age 27)

$\therefore$. that smacky one ... that was just that girl saying there must be heroin in it, I don't know, . . . it could have been kinda amphetamine.' (019, female, age 29)

Finally, only a handful of respondents stated that it was not feasible for Ecstasy tablets to be laced with heroin. Two persons who had used heroin previously provided their reasons:

'Laced with amphetamine, yeah. Laced with heroin--heroin is very expensive, cocaine is very expensive. The chance that [Ecstasy tablets] would be laced with those is so remote . . . People tell me they got hashish cut with opium--that's gonna put the price up 10 times the regular price up from the original. [Also] heroin is not effective orally . . . No, absolute waste of money ... it's like somebody selling cheap jewellery, they're not gonna get a diamond in a cheap jewel to make it sell for a few pounds. l'd be very, very sceptical. It doesn't make sense from any point of view.' (302, male, age 34)

'... that's a load of nonsense . . . it would be too expensive, it would be waste of time ...' (109, male, age 23)

\title{
Discussion
}

Parker et al. (1998, p. 119) concluded that drug users utilize 'cost-benefit assessments' in decisions made about what drugs are consumed, how and in what contexts drugs are taken, and what risks are associated with drugs use and related activities. These decisions are manifested in the drawing of distinct boundaries between drugs that are acceptable and those that are not.

Some writers have expressed concerns regarding the emergence of a trend in popular culture wherein films, pop music and the fashion industry are accused of glamorizing heroin use as 'in' among particularly highly stylized social groupings (Richey, 1998) . In our study, where consumption of Ecstasy and other drugs was often intimately linked to highly developed notions of style and 'coolness' associated with the dance scene, we found little evidence that heroin was regarded in the same light; rather, respondents in the study clearly distinguished Ecstasy from heroin and tended to view heroin and heroin users in negative terms.

Non-opiate users who voice negative views about heroin and injection, in a sense defend and reaffirm their own drug-user status as being acceptable, believing for example that someone else is more dangerous than me'. Klee (1998, p. 49) observed that:

'In societies like the United Kingdom in which heroin is the standard for junkie stereotypes, the image includes personal neglect, criminal tendencies, and violence. The controlled or 
occasional amphetamine user can occupy the high moral ground, assume a low profile, escape the attention of authorities, and enjoy the drug without too much concern.'

The belief that heroin is evil allows Ecstasy users to feel better about their own drug use and facilitates perceptions of a safer, more sensible, and 'recreational' sense of identity within their own drug-user sub-culture. As Woodward $(1997$, p. 2) has argued, ‘. . identity is often most clearly defined by difference, by the marking of inclusion or exclusion, insiders and outsiders, us and them'. Viewing heroin users as 'junkies', 'drop outs' or 'losers' allows Ecstasy users to both situate and represent themselves within a more comforting and reassuring framework. In this sense their views are a mirror image of the official discourses regarding drug use in Northern Ireland in the preceasefire era, defined by a polarized 'other' which is characterized as more serious, more deviant and more threatening.

The views of those respondents who reported that they had consumed Ecstasy tablets that had been laced with heroin (22\%) may also be located within such a framework [14]. It may reflect contemporary 'dope fiend mythology' (Lindesmith, 1940) wherein the belief in Ecstasy laced with heroin serves to enhance the perceived risk about acquiring and using Ecstasy, a walk on the wilder side in a culture where the consumption of such 'recreational' drugs has become increasingly normalized (Parker et al., 1998). The notion of Ecstasy laced with heroin may also serve to protect the 'drug of choice' for non-opiate users. Ecstasy cannot be blamed for the undesireable effects of the drug; rather, some other substance, in this case, heroin, must be responsible for bad experiences. Ecstasy retains its largely virtuous reputation amongst users, and negative experiences are attributed to a familiar but distant 'evil'.

On the surface, the findings suggest that many users of Ecstasy perceive heroin as 'evil' and a drug to avoid. Such a finding provides little support for the simplistic assumption about Ecstasy being a pathway to heroin. That said, preliminary findings from a study in progress of heroin users in Northern Ireland (McElrath, forthcoming), suggest that heroin users too, once had negative images about heroin. Drug users' perceptions about risk can change over time (Rhodes, 1997) through, for example, regular use among members of social groups that are important to the user (United Nations International Drug Control Programme, 1997). Earlier studies showed that 'antidrug propaganda' contributed to a fear of addiction among non-opiate drug users (Feldman, 1977, p. 261) but that these fears subsided with 'everyday observation' of persons who were not addicted. Future research should focus on the reasons that perceptions about heroin change for some drug users who eventually initiate heroin use or injection, despite having once held negative views.

\section{Acknowledgements}

This study was funded by the Northern Ireland Statistics and Research Agency. Points of view are those of the authors.

\section{Notes}

[1] We recognize, however, that distinctions between these drug categories can be obscured.

[2] Heroin users interviewed as part of a study in progress have indicated that several other deaths occurred before the 1998 overdose (McElrath, forthcoming).

[3] In Northern Ireland, notifications for heroin showed an increase since 1995 particularly among youth under the age of 21 years (Higgins \& McElrath, forthcoming). However, studies conducted elsewhere have found that the validity of notification data is limited (Hartnoll et al., 1985; Jay \& McKeganey, 1996) and it is possible that notification data collected in Northern Ireland also are plagued with inconsistencies. Some evidence, for example, has suggested that changes in official data on drug use have more accurately reflected changes in law enforcement and medical practices in the region (Higgins \& McElrath, forthcoming; McEvoy et al., 1998). Self-report studies in the region have shown low levels of heroin use (e.g. $<1 \%$ ) although sampling procedures (e.g. non-random samples) and research design issues (e.g. school-based surveys) may have contributed to the low estimates. Unlike a number of areas in Great Britain and in the Republic of Ireland (namely Dublin), needle exchange programmes and methadone maintenance programmes have not been available in Northern Ireland, so that data from these sources cannot be analysed. Finally, the number of qualitative studies of heroin users in the region also is limited. 
[4] The average age of the sample is fairly consistent with results reported elsewhere. For example, Forsyth (1996) reported a mean age of 24 years in his study of participants in the dance drug scene in Glasgow (91.1\% of those respondents had consumed Ecstasy). A second study of Ecstasy users in Glasgow reported a mean age of 23 (Hammersley et al., 1999). An average age of 27 years was reported by Solowij et al. (1992) in their study of Ecstasy users in Australia.

[5] We examined 'heavy use' of Ecstasy by age. Lifetime use of Ecstasy (in episodes) was recoded into four categories: 2-12, 13-49, 50-99 and 100 or more episodes. Age also was recoded into four categories: 17-21 years, 22-24 years, 25-28 years and 29 and older. The results showed that the percentage of respondents who had used Ecstasy on 100 times or more, ranged from $45 \%$ to $48 \%$ for persons in the three youngest age groups: 17-21 years, 22-24 years and 25-28 years. In contrast, $35 \%$ of persons aged 29 and older had consumed Ecstasy on 100 or more occasions, thus, respondents in the older group were less likely to be characterized as 'heavy users'. The Chi-Square value of 7.808, however, was not statistically significant ( $\mathrm{df}^{\wedge} 9 ; p^{\wedge} 0: 87$ ).

[6] Not included in this category were respondents who believed that they had consumed an Ecstasy tablet that was laced with heroin.

[7] We recognize that the term, 'heavy users' is value-laden and use it here only to describe persons who reported using Ecstasy on at least 100 different occasions.

[8] Negative perceptions included the following descriptions about heroin use or heroin users: negative personal traits (e.g. scummy, creepy, seedy, dirty, stupid, selfish, mad, dangerous, a waste), references to distinct groups (e.g. non-recreational versus recreational use), conscious efforts to 'steer clear' of heroin users, heroin users as 'real' drug users, etc.

[9] We used a Chi-Square test on the basis of its non-parametric properties. Although non-parametric statistics make fewer assumptions about the distribution of the sample, they still are most appropriate for random samples. Respondents in our sample were not selected randomly and although we report Chi-Square tests and associated probabilities, we also encourage readers to reach their own conclusions.

[10] Certain Ecstasy tablets have suggested that the tablets have been manufactured in Amsterdam (e.g. 'Double Amsterdam', 'Pink Tulips', 'Windmills', 'Green Windmills'), a finding that suggests the possibility of a marketing strategy on the part of dealers.

[11] Three per cent of the samples were not certain as to whether they had ever consumed such tablets.

[12] Nevertheless, he continued to use Ecstasy.

[13] A respondent who first used in Wales in 1989 reported that 'China White' was the brand of Ecstasy that he first used and described that experience as being very pleasurable (204). Another (027) respondent also reported a positive E experience after consuming a tablet called 'China White'. 'China White' has been used as slang term for heroin. Although these respondents did not appear to make the connection between the tablet labels and 'China White', other users may have.

[14] The belief in this myth appeared to be related in part to street slang or drug nomenclature, i.e. the term, 'Smacky E'. 


\section{References}

BECK, J. \& ROSENBAUM, M. (1994). Pursuit of Ecstasy: the MDMA experience. Albany, NY: SUNY.

Belfast Telegraph (1997a) . Our heroin hell, 15 August.

Belfast Telegraph (1997b). Help fight our heroin horrors, 15 August.

Belfast Telegraph (1998). Heroin abuse on increase, 11 September.

Belfast Telegraph (1999). No complacency on our part: Ingram, 30 April.

COOMBER, R. (1997) . The adulteration of drugs: what dealers do to illicit drugs, and what they think is done to them. Addiction Research, 5, pp. 297-306.

DUNLAP, E., JOHNSON, B., SANABRIA, H., Holliday, E., LIPSEY, V., BARNETT, M., HOPKINS, W., SOBEL, I., RANDOLPH, D. \& CHIN, K. (1990). Studying crack users and their criminal careers: the scientific and artistic aspects of locating hard-to-reach subjects and interviewing them about sensitive topics. Contemporary Drug Problems, 17, pp. 121-44.

FELDMAN, H.W. (1977). A neighbourhood history of drug switching. In R.S. WEPPNER (Ed.), Street Ethnography: selected studies of crime and drug use in natural settings (pp. 249-78). Beverly Hills, CA: Sage.

FINNIGIN, F. (1996). How non-heroin users perceive heroin users and how heroin users perceive themselves. Addiction Research, 4, pp. 25-32.

FORSYTH, A.J.M. (1995) . Ecstasy and illegal drug design: a new concept in drug use. International Journal of Drug Policy, 6, pp. 193-209.

FORSYTH, A.J.M. (1996). Places and patterns of drug use in the Scottish dance scene. Addiction, 91, pp. 511-21.

FRASER, A., GAMBLE, L. \& KENNETT, P. (1991) . Into the Pleasure dome ... Druglink, November/December, pp. 12-13.

HAMMERSLEY, R., DITTON, J., SMITH, I. \& SHORT, E. (1999) . Patterns of Ecstasy use by drug users. British Journal of Criminology, 39, pp. 625-47.

HARTNOLL, R., MITCHESON, M., LEWIS, R. \& BRYER, S. (1985) . Estimating the prevalence of opioid dependence. Lancet, 26 January, pp. 203-05.

HAY, G. \& MCKEGANEY, N. (1996) . Estimating the prevalence of drug misuse in Dundee, Scotland: an application of capture-recapture methods. Journal of Epidemiology and Community Health, 50, pp. 469-72.

HIGGINS, K. \& MCELRATH, K. The trouble with peace: the cease-fires and their impact on drug use among youth in Northern Ireland. Youth and Society, forthcoming.

HOLLYWOOD, B. (1997). Dancing in the dark: Ecstasy, the dance culture and moral panic in post ceasefire Northern Ireland. Critical Criminology, 8, pp. 62-77.

KLEE, H. (1998). The love of speed: an analysis of the enduring attraction of amphetamine sulphate for British youth. Journal of Drug Issues, 28, pp. 33-56.

LIFELINE (1996), Ecstasy: frequently asked questions, Manchester: Author.

LINDESMITH, A.R. (1941 or 1940). Dope fiend mythology. Journal of Criminal Law and Criminology, 32, pp. 199-208.

MALYON, T. (1995) . Dancing with death. New Statesman and Society, 7, pp. 24-41.

MCELRATH, K. (2000) . Heroin use in Northern Ireland. Final Report. Belfast: Northern Ireland Statistics and Research Agency.

MCELRATH, K. \& MCEVOY, K. (1999). Ecstasy Use in Northern Ireland. Belfast, HMSO.

MCEVOY, K., MCELRATH, K. \& HIGGINS, K. (1998). Does Ulster still say no? Drugs, politics and propaganda in Northern Ireland. Journal of Drug Issues, 21, pp. 127-55.

MCKEGANEY, N. \& BARNARD, M. (1992). AIDS, Drugs and Sexual Risk: lives in the balance. Buckingham: Open University Press.

MILROY, C.M., CLARK, J.C. \& FORREST, A.R.W. (1996). Pathology of deaths associated with 'ecstasy' and 'eve' misuse. Journal of Clinical Pathology, 49, pp. 149-53. 
PARKER, H., ALDRIDGE, J. \& MEASHAM, F. (1998). Illegal Leisure: the normalization of adolescent recreational drug use. London: Routledge.

POWER, R., POWER, T. \& GIBSON, N. (1996) . Attitudes and experience of drug use amongst a group of London teenagers. Drugs: education, prevention and policy, 3, pp. 71-80.

RHODES, T. (1997) . Risk theory in epidemic times: sex, drugs and the social organisation of 'risk behaviour'. Sociology of Health and Illness, 19, pp. 208-27.

RICHEY, W. (1998) . Heroin finds a market in young people. Christian Science Monitor, 23 March, website.: http://www/csmonitor.com/durable/1998/03/23/us/us.1/html.

SAUNDERS, N. (1998). Trends in quality in January 1998. Website: http://ecstasy.org/analysis.htm.

SOLOWIJ, N. Hall,W\& Lee, N. (1992) . Recreational MDMA use in Sydney: a profile of 'ecstasy' users and their experiences with the drug. British Journal of Addiction, 87, pp. 1161-72.

TURNER, J. (1998) . Trade in a well-to-do town. Irish News, 29 October.

UNITED NATIONS INTERNATIONAL DRUG CONTROL PROGRAMME (1997). World Drug Report. Oxford: Oxford University Press.

WIBBERLEY, C. \& PRICE, J.F. (1998) . Young people's drug use: facts and findings. Journal of Child Health Care, 2, pp. 138-42.

WOODWARD, K. (Ed.) (1997) . Identity and Difference. London: Sage. 